\title{
Evaluation of electrophoretic methods for typing methicillin-resistant Staphylococcus aureus
}

\author{
M. A. GASTON, P. S. DUFF, J. NAIDOO, K. ELLIS, J. I. S. ROBERTS, J. F. RICHARDSON, \\ R. R. MARPLES and E. M. COOKE
}

Division of Hospital Infection, Central Public Health Laboratory, 61 Colindale Avenue, London NW9 5 HT

\begin{abstract}
Summary. Three electrophoretic methods of typing methicillin-resistant Staphylococcus aureus (MRSA) strains - plasmid profiles (PP), whole-cell protein profiles (WCPP) and immunoblotting profiles (IP) - were evaluated and compared with phage typing. The results obtained with isolates from 12 outbreaks were compared both within the outbreaks, to determine the consistency of results, and between outbreaks. There was generally good agreement between the typing methods but in only six outbreaks did all four methods indicate the same relationship between isolates. WCPP comprised more than 50 bands; when differences occurred, they were seen in only a few bands. In contrast, IP comprised only one or two major bands and the differences were much easier to interpret. The PPs of many of the isolates were similar; many isolates contained a plasmid of mol. wt (18-25) $\times 10^{6}$. In several outbreaks both WCPP and IP showed minor differences between isolates that were not apparent with phage typing. When comparisons were made between the 12 index strains and an isolate representing the London epidemic MRSA strain, phage typing and WCPP were the most discriminatory methods; both gave nine distinct patterns, whereas there were eight IPs and only six PPs amongst the 13 strains. It was concluded that both WCPP and IP could provide valuable epidemiological data on MRSA and that IP was the easiest of the three methods to interpret.
\end{abstract}

\section{Introduction}

The increased isolation of methicillin-resistant Staphylococcus aureus (MRSA) and the spread of a particular strain throughout London and the southeast of England has required careful monitoring of isolates by microbiologists and infection-control staff. Bacteriophage typing of $S$. aureus is widely accepted as a convenient and highly discriminatory method of identifying index strains for epidemiological studies. Unfortunately, many MRSA strains are only weakly sensitive, or not sensitive at all, to the current international set of phages, and other methods are required to document the spread of these multi-resistant strains.

One approach adopted in our laboratory is the use of supplementary phages to which MRSA strains are susceptible. These have proved useful in the definition of the Thames epidemic strain (EMRSA; Marples and Cooke, 1985) but the information provided by this approach is still not

Received 2 July 1987; accepted 22 Oct. 1987. totally satisfactory (Richardson et al., 1988). An alternative approach with electrophoretic techniques as primary methods of subdividing strains of $S$. aureus has been used (Krikler et al., 1986; Stephenson et al., 1986). Stephenson et al. (1986) examined $S$. aureus proteins separated by polyacrylamide gel electrophoresis (PAGE) with autoradiography and used the resulting patterns to compare isolates, whereas Krikler et al. (1986) showed that some strains of $S$. aureus gave distinct patterns after immunoblotting with normal human sera.

We have evaluated the potential of PAGE methods as routine typing systems for several nosocomial pathogens, including $S$. aureus. In this report we present the results of a study of whole cell polypeptide, immunoblotting and plasmid profiles of MRSA, compared with phage typing. Typing patterns of representative strains from 12 outbreaks in the UK were compared both within each outbreak, to determine the consistency of results, and between outbreaks, to establish the relationships between these strains and the EMRSA currently prevalent in south-east England. 


\section{Materials and methods}

\section{Strains and phage typing}

Strains of S. aureus were selected from isolates sent to the Central Public Health Laboratory for typing in 1985 and 1986. Twelve centres were identified as having an outbreak with a single predominant strain of MRSA that was distinguishable by phage type from the EMRSA. Five isolates from each centre were chosen to represent the possible phenotypic spread of the index strain. Isolates representing the EMRSA strain from an Essex hospital were included for comparison. Isolates were phage typed with the international set of phages, at RTD and $100 \times$ RTD. Four supplementary phages, 88A, 90, $83 \mathrm{C}$ and 932 , currently used in our laboratory for additional discrimination, were also tested at $100 \times$ RTD.

\section{Antisera}

Antisera against three strains of $S$. aureus were raised in New Zealand white rabbits. Strains used for vaccination were an isolate of EMRSA, a non-epidemic MRSA isolate, and an antibiotic-sensitive strain of $S$. aureus. The vaccines were prepared from cells grown overnight at $37^{\circ} \mathrm{C}$ in nutrient broth (Oxoid) supplemented with $\mathrm{Na} \mathrm{Cl} 2.5 \% \mathrm{w} / \mathrm{v}$ and glucose $0.2 \%$ w/v. Cells were harvested from $100 \mathrm{ml}$ of culture medium by centrifugation, washed once and resuspended in $0.5 \%$ formol saline to a final concentration of $3 \times 10^{9} \mathrm{cells} / \mathrm{ml}$, and incubated overnight at $4^{\circ} \mathrm{C}$ to destroy cell viability. Each vaccine was given via the marginal ear vein as follows: day 1 , $0.1 \mathrm{ml}$; day $2,0.2 \mathrm{ml}$; day $3,0.4 \mathrm{ml}$; day $9,0.4 \mathrm{ml}$; day $10,0.6 \mathrm{ml}$; day $11,0.8 \mathrm{ml}$; day $17,0.8 \mathrm{ml}$; day $18,1.0 \mathrm{ml}$; and day $19,1.0 \mathrm{ml}$. Rabbits were test bled on day 25 and exsanguinated on day 26 . The titres in slide agglutination tests were between 100 and 1000 .

\section{Antibiotic-sensitivity testing}

Antibiotic-sensitivity testing was performed by the Stokes' Method (Stokes and Waterworth, 1972) on Isosensitest Agar (Oxoid) with disks containing the following concentrations of antibiotics: penicillin 1 unit, tetracycline $10 \mu \mathrm{g}$, erythromycin $10 \mu \mathrm{g}$, lincomycin $2 \mu \mathrm{g}$, trimethoprim $2.5 \mu \mathrm{g}$, chloramphenicol $10 \mu \mathrm{g}$, gentamicin $10 \mu \mathrm{g}$, kanamycin $30 \mu \mathrm{g}$, tobramycin $10 \mu \mathrm{g}$, neomycin $30 \mu \mathrm{g}$, streptomycin $50 \mu \mathrm{g}$, amikacin $10 \mu \mathrm{g}$, netilmicin $10 \mu \mathrm{g}$, spectinomycin $200 \mu \mathrm{g}$, sisomicin $10 \mu \mathrm{g}$, methicillin $10 \mu \mathrm{g}$. Sensitivity to propamidine was determined on plates containing propamidine isothionate $100 \mu \mathrm{g} / \mathrm{ml}$.

\section{Plasmid DNA analysis}

Plasmid analysis was performed on agarose gels as previously described (Naidoo, 1984). A loopful of plate culture was suspended in $1 \mathrm{ml}$ of salt solution $(2.5 \mathrm{M}$ $\mathrm{NaCl}, 0.05 \mathrm{M}$ EDTA, $\mathrm{pH} 7.5$ ) and treated with lysostaphin $50 \mu \mathrm{g} / \mathrm{ml}$ for $15 \mathrm{~min}$, at $37^{\circ} \mathrm{C}$. Lysis was achieved by addition of $1.6 \mathrm{ml}$ of detergent mixture (Brij-58 1.2\%, sodium deoxycholate $0.5 \%, 0.02 \mathrm{M}$ EDTA, $\mathrm{pH} 8.4$ ). After centrifugation $(15000 \mathrm{rpm}, 30 \mathrm{~min})$ the cleared lysate was treated with protease $50 \mu \mathrm{g} / \mathrm{ml}$. The DNA was precipitated with an equal volume of isopropanol. Electrophoresis was performed in $0.8 \%$ agarose gels at $100 \mathrm{~V}$ for $4 \mathrm{~h}$.

\section{Protein electrophoresis}

Sodium dodecylsulphate-polyacrylamide gel electrophoresis (SDS-PAGE) was performed by the method of Laemmli (1970) with $10 \%$ resolving gels. Proteins were detected by staining overnight with acetic acid $10 \%$ $\mathrm{v} / \mathrm{v}$, methanol $30 \% \mathrm{v} / \mathrm{v}$ and Coomassie blue $0.1 \% \mathrm{w} / \mathrm{v}$.

Whole-cell antigens were prepared as follows: strains were grown overnight at $37^{\circ} \mathrm{C}$ on nutrient agar (Oxoid) and bacterial growth was harvested in $3 \mathrm{ml}$ of phosphate buffered saline (PBS). Cells were collected by centrifugation and resuspended in $1 \mathrm{ml}$ of PBS containing lysostaphin (Sigma) $25 \mu \mathrm{g} / \mathrm{ml}$ and incubated at $37^{\circ} \mathrm{C}$ for $15 \mathrm{~min}$. RNAase and DNAase (Sigma) were added to final concentrations of $30 \mu \mathrm{g} / \mathrm{ml}$ and the mixtures were incubated for a further $15 \mathrm{~min}$. An equal volume of double strength sample buffer was added and the extract was boiled for $5 \mathrm{~min} ; 10 \mu \mathrm{l}$ were applied to each lane.

\section{Electrophoretic transfer and immunoblotting}

Separated components from SDS-PAGE gels were transferred to nitrocellulose paper by the method of Towbin et al. (1979). Electrotransfer was performed overnight at $4^{\circ} \mathrm{C}$ at $28 \mathrm{~V}$. The transfer buffer contained $25 \mathrm{~mm}$-Tris, $192 \mathrm{mM}$ glycine and methanol $20 \% \mathrm{v} / \mathrm{v}, \mathrm{pH}$ 8.3. The nitrocellulose paper was soaked in BSA $3 \% \mathrm{w} / \mathrm{v}$ in PBS for $30 \mathrm{~min}$ at room temperature with constant agitation to saturate any non-specific protein-binding sites. The primary antibody was then added to a final dilution of 1 in 50 and incubated for $1 \mathrm{~h}$ with continuous agitation. The paper was washed five times in PBS and incubated for a further $1 \mathrm{~h}$ with alkaline phosphataseconjugated goat anti-rabbit IgG diluted 1 in 1000 in PBS containing BSA $3 \%$. The paper was washed as described above and incubated for $10 \mathrm{~min}$ in $50 \mathrm{~mm}$ Tris buffer, $\mathrm{pH}$ $7 \cdot 5$, containing fast red violet $1 \mathrm{mg} / \mathrm{ml}$ and naphthol ASMX phosphate (Sigma) $1 \mathrm{mg} / \mathrm{ml}$, rinsed twice in distilled water, dried and photographed.

\section{Results}

\section{Relationships between isolates from the same outbreak}

Generally there was good agreement between the four typing systems in each outbreak. In six, all four systems indicated the same relationship between isolates. In four, electrophoretic typingwhole-cell polypeptide profiles and immunoblotting profiles - and phage typing defined the same rela- 
tionships between strains but plasmid profiles did not correspond completely. In one outbreak, electrophoretic typing showed differences between isolates that could not be seen with either phage typing or plasmid profiling, and in the remaining outbreak all three systems indicated slightly different relationships between each isolate.

The results obtained with isolates from one of the outbreaks (V) are shown to illustrate the general pattern of results. All five isolates (EN1-EN5) were non-typable by the international set of phages and, although reacting weakly with one of the supplementary phages, they could not be distinguished by phage typing. There were differences in the susceptibility of these isolates to tetracycline and erythromycin but their plasmid profiles were identical; each contained a single plasmid of mol. wt $18 \times$ $10^{6}$. The whole-cell protein profiles given by EN3 and EN 5 were indistinguishable but the other three isolates could be separated from each other and from EN3/5 on the basis of one or more high-mol. wt bands (fig. 1). In immunoblotting, the mobility of the major band in isolates EN2-EN5 was identical and reproducibly greater than the similar band in isolate EN1. Isolates EN3 and EN5 gave indistinguishable immunoblotting profiles but the other isolates could be distinguished by minor differences in the high-mol. wt section of the blot.

\section{Relationships between isolates from different outbreaks}

Phage typing. The international set of typing phages was only poorly reactive at RTD but several strong lytic reactions were obtained with phages at $100 \times$ RTD and with the supplementary phages (table I). Three pairs of strains were indistinguishable: strains II and III gave strong reactions with phages $83 \mathrm{~A}, 84,85$, and with two supplementary phages; strains IV and VI were lysed strongly by two supplementary phages; and strains I and VIII

\section{Whole cell polypeptides}

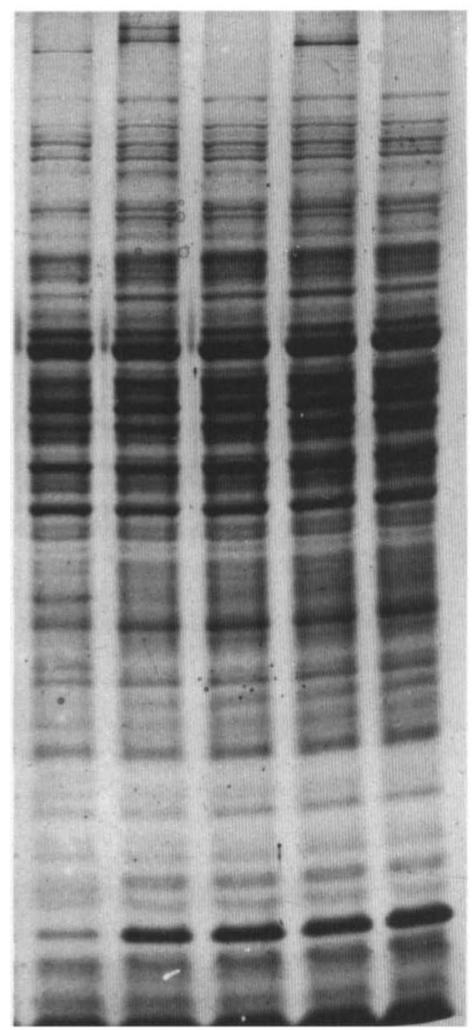

\section{Immunoblot}

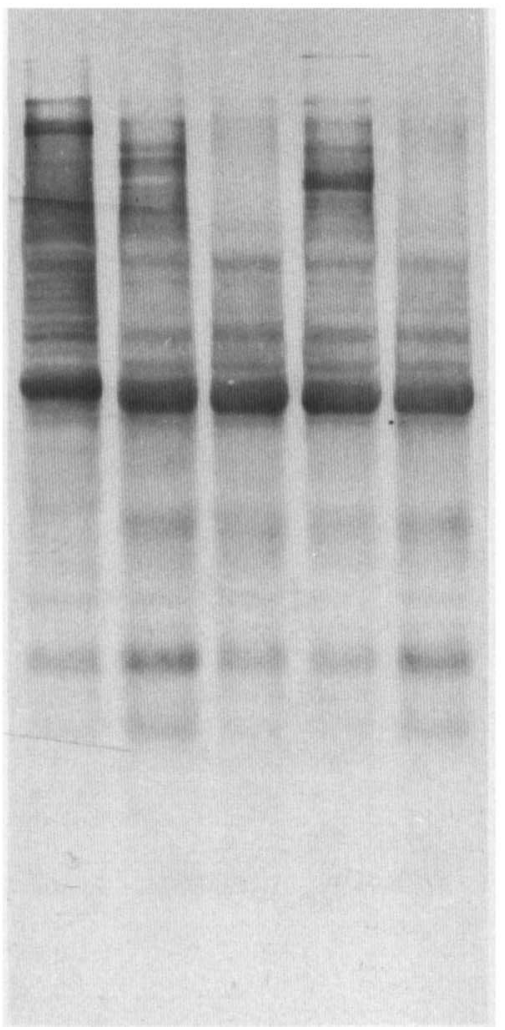

Plasmid profiles

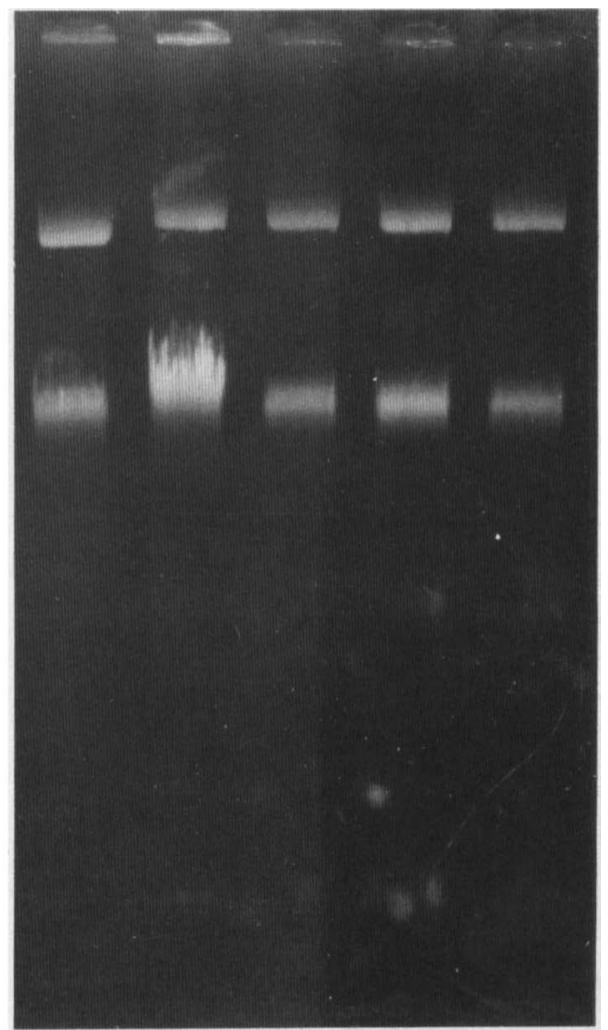

\section{EN1 EN2 EN3 EN4 EN5}

EN1

Fig. 1. Electrophoretic typing patterns of MRSA isolates from outbreak V (see legend for figures 2, 3 and 4). 


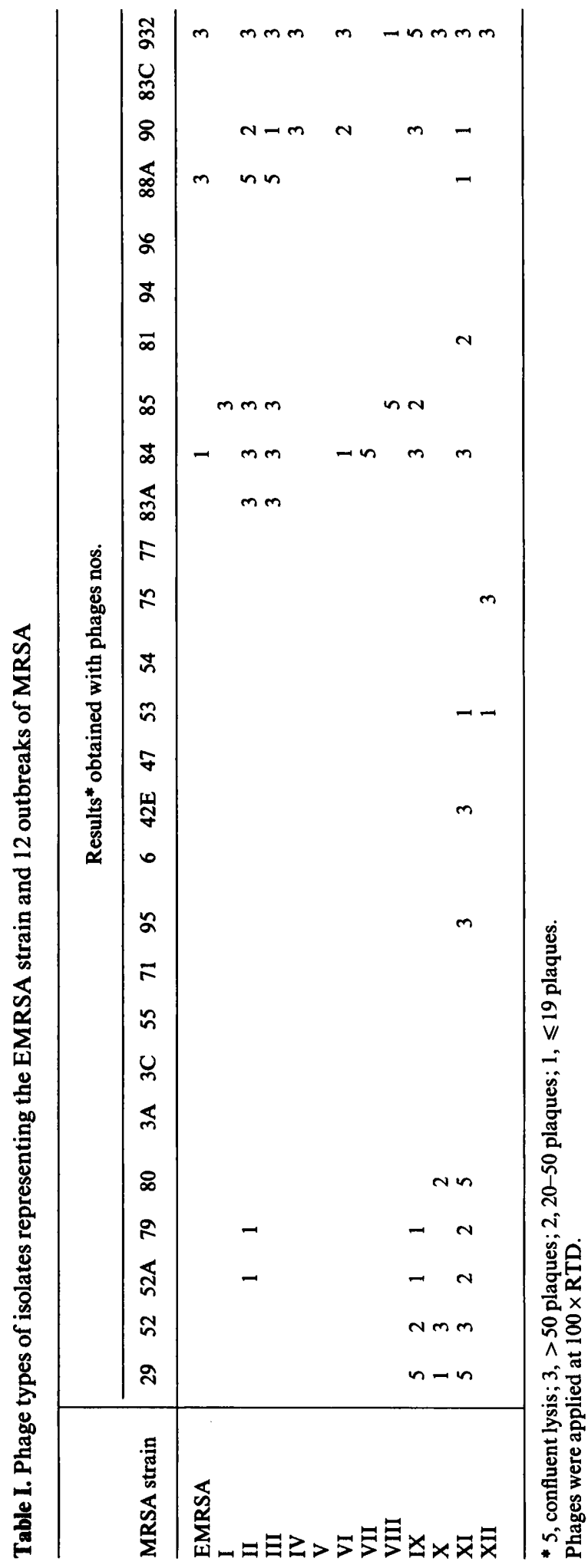


gave strong reactions with phage 85 . All the other strains were distinguishable by at least one reaction. The supplementary phages made a valuable contribution to the phage typing of these isolates. Phage typing was the most discriminatory system; there were ten patterns of lysis amongst the 13 index strains.

Plasmid profiles. Ten of the 12 outbreak strains had one large plasmid of mol. wt c. $20 \times 10^{6}$ (fig. 2). In EMRSA strains this plasmid codes for aminoglycoside and propamidine resistance. However, three strains (IX, XI and XII) were sensitive to these agents, which suggested that the $20 \times 10^{6}$. mol. wt plasmid in these strains was not related to the aminoglycoside-propamidine resistance plasmid. Two strains, II and III, contained a plasmid of mol. wt $1.2 \times 10^{6}$ equivalent to the cryptic plasmid found in many of the EMRSA isolates (note that only one of the EMRSA controls on this gel contained this plasmid). The lack of plasmid diversity in these strains made interpretation of the profiles difficult. The comparison of antimicrobial and plasmid data indicated that five of the index strains were indistinguishable from the EMRSA.

Whole-cell polypeptide profiles. Each strain was compared with others on at least four gels. Although the patterns were consistent within the same gel, they varied between gels, even with the same extracts. Therefore comparisons could be made only between profiles on the same gel. Each profile contained over 50 bands and there was a broad similarity between patterns; the vast majority of bands was present in all the profiles (fig. 3). Three strains (IV, VI and XI) were clearly distinct in most gels and minor differences could be seen in six other strains. Three strains (table II) could not be distinguished from each other or from the EMRSA.

Immunoblotting profiles. The three antisera gave slightly different immunoblotting profiles with the strains but the major characteristics of each profile

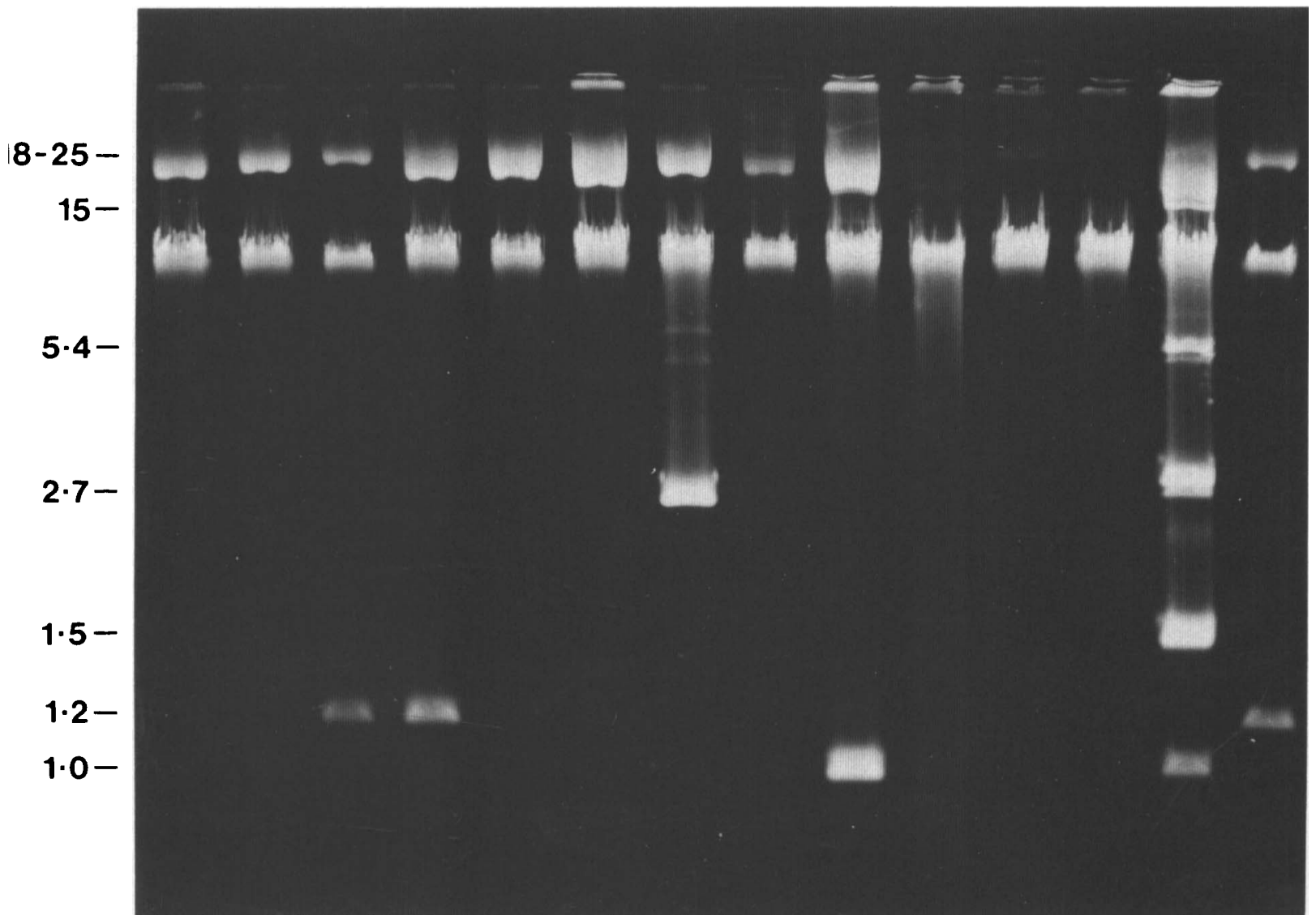

\section{$\begin{array}{llllllllllllll}\text { EI } & \text { I } & \text { II } & \text { III } & \text { IV } & \text { V } & \text { VI } & \text { VII } & \text { VIII } & \text { IX } & X & \text { XI } & \text { XII } & E 2\end{array}$}

Fig. 2. Plasmid profiles of strains from 12 outbreaks of MRSA (I-XII) and two isolates representing the epidemic MRSA strain prevalent in south-east England (E1 and E2). Vertical lettering indicates mol. wts $\left(10^{6}\right)$. 


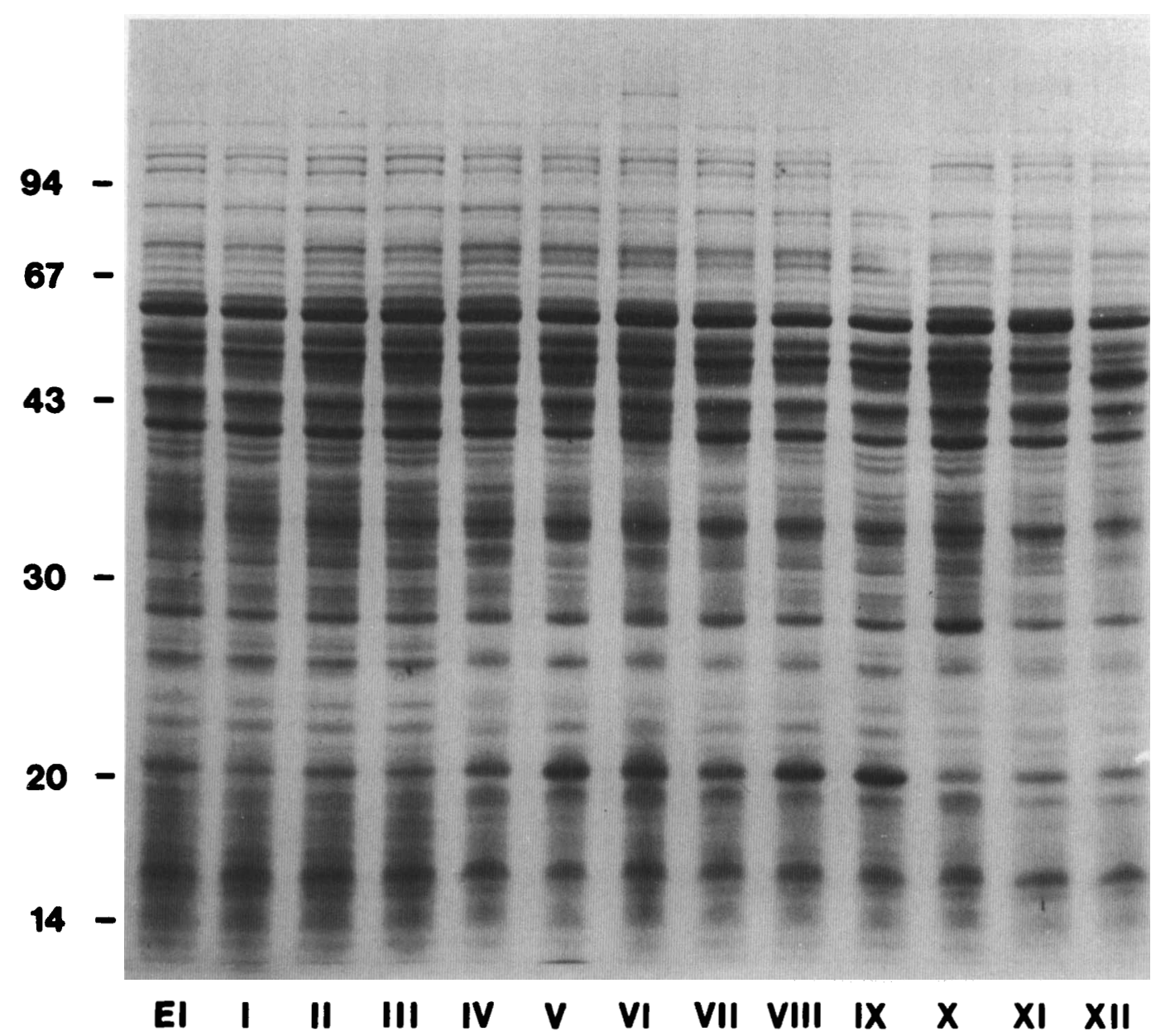

Fig. 3. Whole-cell protein profiles of strains from 12 outbreaks of MRSA (I-XII) and an isolate representing the epidemic MRSA strain prevalent in south-east England (E1). Proteins were separated on a 10\% acrylamide gel and stained with Coomassie blue. Several distinguishing bands have not been visualised in this figure, indicating the poor reproducibility of these profiles.

were broadly similar and the same interpretation, of relationships between strains were produced. Three strains (I, II and III) gave very similar blots, which were similar to the blots from EMRSA (fig. 4). Strains IV, V and VI gave distinct patterns. Strains VII, VIII and IX were essentially indistinguishable on immunoblotting profile. Strains X, XI and XII gave similar blots but were consistently distinguishable on the basis of a strong double reaction in XII and the slight difference in mol. wt of the strong reaction in blots from strains $X$ and XI. The similarity between EMRSA and strains I, II and III may merely reflect the absence of a strong immunoblotting reaction, rather than the presence of positive characteristics that represented a relationship between these strains.

\section{Comparison of electrophoretic methods with phage typing}

Whole-cell polypeptide profiles were the most difficult to interpret. They were complex and strains had to be run adjacent to each other for accurate comparison. It was less discriminatory than phage typing but it was able to distinguish between one pair of isolates (IV and VI) that were indistinguishable by phage typing. In contrast, the patterns obtained by immunoblotting were much easier to interpret and the method was less susceptible to variable running conditions. It could not distinguish between three isolates (VII, VIII and IX) that were clearly distinguishable by phage type. Strain IX consistently gave a weaker reaction in immunoblotting but the reaction was due to an antigen with the 


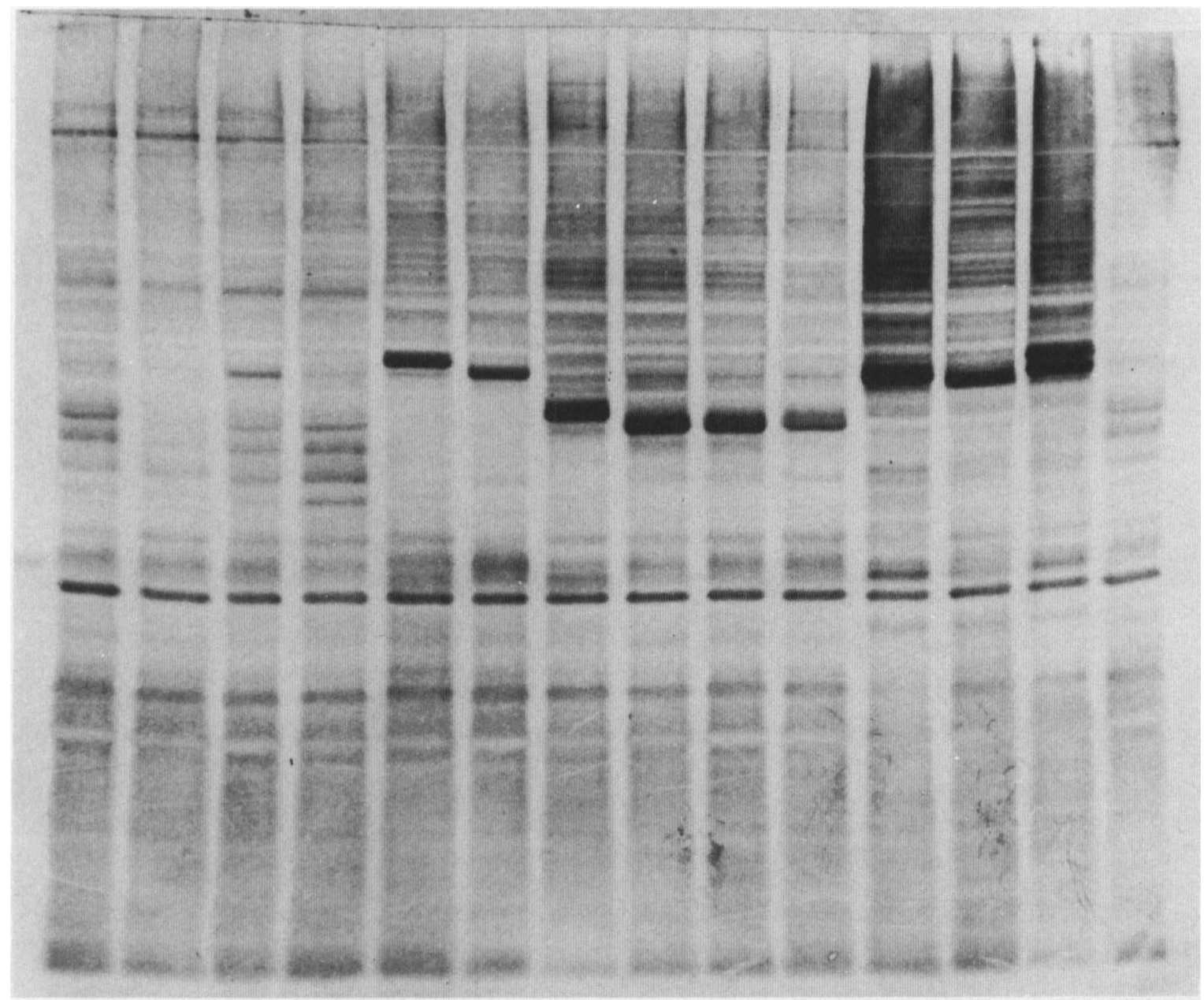

\section{$\begin{array}{llllllllllllll} & \text { EI I } & \text { II } & \text { III } & \text { IV } & V & \text { VI } & \text { VII } & \text { VIII } & I X & X & X I & X I I & E I\end{array}$}

Fig. 4. Immunoblotting profiles of strains from 12 outbreaks of MRSA (I-XII) and an isolate representing the epidemic MRSA strain prevalent in south-east England (E1). Antigens were separated on a $10 \%$ acrylamide gel, transferred to nitrocellulose and treated with antisera raised against a MRSA strain. Immunoglobulins were detected with an anti-rabbit IgG-alkaline phosphatase system.

same mobility in SDS-PAGE. Plasmid analysis by mobility in agarose gels was the least discriminatory method. This was partly due to the low plasmid content of these isolates but also to the variability of plasmid content of isolates known to represent the same strain, i.e., EMRSA.

\section{Discussion}

The purpose of this analysis was to determine the suitability of electrophoretic methods for typing $S$. aureus. Our results, and those of previous studies (Clink and Pennington, 1987; Krikler et al., 1986; Stephenson et al., 1986) clearly show that electrophoretic methods can provide valuable epidemio- logical information that may be used in isolation or to confirm the result of phage typing. The two groups of workers who have studied electrophoretic typing methods for $S$. aureus have, to some extent, come to different conclusions. Stephenson et al. (1986) showed that isolates from an outbreak in a cardiothoracic ward were indistinguishable from the EMRSA strain but could be distinguished from other strains. The ${ }^{35} \mathrm{~S}$-labelled proteins used by Stephenson et al. (1986) can be equated with the profiles produced by total cell proteins that Clink and Pennington (1987) studied. Yet these workers found that only minor variations in band patterns were seen between strains, and concluded that SDS-PAGE of polypeptides of whole-cell extracts 
Table II. Relationship between isolates defined by phage typing, plasmid profiles, whole cell polypeptides and immunoblotting

\begin{tabular}{lcccc}
\hline $\begin{array}{l}\text { Outbreak } \\
\text { strain no. }\end{array}$ & $\begin{array}{c}\text { Phage typing } \\
\text { pattern }\end{array}$ & $\begin{array}{c}\text { Plasmid } \\
\text { profile* }\end{array}$ & $\begin{array}{c}\text { Whole-cell } \dagger \\
\text { polypeptide } \\
\text { profile }\end{array}$ & $\begin{array}{c}\text { Immunoblotting } \\
\text { profile }\end{array}$ \\
\hline EMRSA & 1 & 1 & 1 & 1 \\
I & 2 & 1 & 1 & 1 \\
II & 3 & 1 & 2 & 1 \\
III & 3 & 1 & 2 & 1 \\
IV & 4 & 1 & 3 & 2 \\
V & NT & 1 & 4 & 3 \\
VI & 4 & 2 & 5 & 4 \\
VII & 5 & 1 & 6 & 5 \\
VIII & 2 & 3 & 1 & 5 \\
IX & 6 & 4 & 1 & 6 \\
X & 7 & 5 & 7 & 7 \\
XI & 8 & NPD & 8 & 8 \\
XII & 9 & 6 & 9 & \\
\hline
\end{tabular}

Numerical code indicates distinct strains as defined by the typing method. NPD $=$ No plasmids detected.

* Strains defined by plasmid profiles include antimicrobial resistance data.

$\dagger$ Minor difference in patterns could not be distinguished on all gels.

did not readily provide data for the establishment of typing schemes.

We agree with Clink and Pennington (1987) that the patterns given by whole-cell polypeptides of different strains are very similar, yet the differences that do occur can be used to distinguish between some strains. It should be stressed that we found that these patterns are difficult to reproduce, so that strains could be compared only on the same gel, and that some differences were very minor. In practice this means that several gel runs must be made before conclusions can be reached. In contrast, immunoblotting of $S$. aureus strains gave patterns that could be used to separate some strains and this method has the potential to be developed into an alternative or ancillary typing method for routine use.

Several studies have shown the value of plasmid analysis in epidemiological investigations of $S$. aureus infections (Kozarsky et al., 1986). Three studies in which phage typing was compared with plasmid analysis on MRSA isolates noted the unsatisfactory reaction of the phages at RTD and lower dilutions (Archer and Mayhall, 1983; Cookson et al., 1986; Rhinehart et al., 1987). The latter two studies found plasmid analysis a more useful epidemiological tool for MRSA outbreaks especially when combined with aminoglycoside-inactivating enzymes or restriction-endonuclease digestion. We suggest that although plasmid analysis is easy to perform, it is the least useful of the electrophoretic methods for long-term studies. The EMRSA isolates in fig. 2 vary in the possession of the cryptic plasmid of mol. wt $1.2 \times 10^{6}$ frequently seen in EMRSA, and gentamicin-resistant EMRSA can lose the high-mol. wt plasmid coding for aminoglycoside resistance. Therefore, plasmid content can vary in isolates of the same strain, particularly if isolates from different locations are examined.

Lacey and Grinsted (1973) considered that all, or almost all, isolates of MRSA had evolved from a single clone. More recent genetic analysis of MRSA from two London hospitals indicated that they were similar to the epidemic type from eastern Australia but could be distinguished from isolates from hospitals in Dublin (Townsend et al., 1987). Our electrophoretic results, and the results of phage typing of MRSA from many hospitals in the UK, clearly indicate that if isolates of MRSA do represent a single clone, then they have diverged to the extent that different strains can be readily distinguished.

New systems of typing have to be evaluated on the basis of their reactivity (typing capacity), their ability to discriminate between distinct strains, and their reproducibility. The typing capacity of these electrophoretic methods for $S$. aureus is essentially $100 \%$ except for those strains that do not contain plasmids, and they can be used to discriminate between strains. Although most of the epidemic isolates were distinguishable in our study and, 
therefore, could be considered to represent distinct strains, we were unable to formulate any definitive parameters that could be used to separate one strain from another. The electrophoretic patterns were distinguished on the basis of subjective analysis only and this is an unsatisfactory basis for a typing scheme. This interpretive problem must be addressed if electrophoretic typing is to become an

\section{REFERENCES}

Archer G L, Mayhall C G 1983 Comparison of epidemiological markers used in the investigation of an outbreak of methicillin-resistant Staphylococcus aureus infections. Journal of Clinical Microbiology 18: 395-399.

Clink J, Pennington T H 1987 Staphylococcal whole-cell polypeptide analysis : evaluation as a taxonomic and typing tool. Journal of Medical Microbiology 23: 41-44.

Cookson B, Talsania H, Naidoo J, Phillips I 1986 Strategies for typing and properties of epidemic methicillin-resistant Staphylococcus aureus. European Journal of Clinical Microbiology 5: 702-709.

Kozarsky P E, Rimland D, Terry P M, Wachsmuth K 1986 Plasmid analysis of simultaneous nosocomial outbreaks of methicillin-resistant Staphylococcus aureus. Infection Control 7: $577-581$.

Krikler S J, Pennington T H, Petrie D 1986 Typing of strains of Staphylococcus aureus by Western blot analysis of culture supernates. Journal of Medical Microbiology 21 : 169-171.

Lacey R W, Grinsted J 1973 Genetic analysis of methicillinresistant strains of Staphylococcus aureus: evidence for their evolution from a single clone. Journal of Medical Microbiology 6: $511-526$.

Laemmli U K 1970 Cleavage of structural proteins during the assembly of the head of bacteriophage T4. Nature 227: 680685.

Marples R R, Cooke E M 1985 Workshop on methicillin- established tool in clinical microbiology. Pattern reproducibility appears to be quite low, particularly for whole-cell protein profiles and this, together with the relative complexity of these methods, may hinder their application to the day-to-day surveillance of hospital isolates of $S$. aureus. However they may be useful with isolates which are non-typable with phages.

resistant Staphylococcus aureus held at the headquarters of the Public Health Laboratory Service on 8 January 1985. Journal of Hospital Infection 6 : 342-348.

Naidoo J 1984 Interspecific co-transfer of antibiotic resistance plasmids in staphylococci in vivo. Journal of Hygiene 93 : 5966.

Rhinehart E et al. 1987 Nosocomial clonal dissemination of methicillin-resistant Staphylococcus aureus: elucidation by plasmid analysis. Archives of Internal Medicine 147: 521524.

Richardson J F, Chittasobhon N, Marples R R 1988 A supplementary phage set for the investigation of methicillinresistant strains of Staphylococcus aureus. Journal of Medical Microbiology 25: 67-74.

Stephenson J R, Crook S J, Tabaqchali S 1986 New method for typing Staphylococcus aureus resistant to methicillin based on sulphur-35 methionine labelled proteins: its application in an outbreak. British Medical Journal 293: 581-583.

Stokes E J, Waterworth P M 1972 Antibiotic sensitivity tests by diffusion methods. Association of Clinical Pathologists Broadsheet No. 55.

Towbin H, Staehelin T, Gordon J 1979 Electrophoretic transfer of proteins from polyacrylamide gels to nitrocellulose sheets: procedure and some applications. Proceedings of the National Academy of Sciences of the USA 76: 4350-4354.

Townsend DE et al. 1987 The international spread of methicillinresistant Staphylococcus aureus. Journal of Hospital Infection 9: $60-71$. 